\title{
Methods of assessing extinction risk in marine fishes
}

\author{
Nicholas K Dulvy ${ }^{1}$, Jim R Ellis ${ }^{1}$, Nicholas B Goodwin ${ }^{2}$, Alastair Grant ${ }^{3}$, John D Reynolds ${ }^{2}$ \& Simon Jennings ${ }^{1}$ \\ ${ }^{1}$ Centre for Environment, Fisheries and Aquaculture Science, Lowestoft Laboratory, Pakefield Road, Lowestoft, Suffolk \\ NR33 OHT; ${ }^{2}$ School of Biological Sciences, University of East Anglia, Norwich NR4 7TJ; ${ }^{3}$ School of Environmental Sciences, \\ University of East Anglia, Norwich, NR4 7TJ, UK
}

\begin{abstract}
The decline and disappearance of species from large parts of their former geographical range has become an important issue in fisheries ecology. There is a need to identify which species are at risk of extinction. The available approaches have been subject to considerable debate - particularly when applied to commercially exploited species. Here we have compiled methods that have been used or may be used for assessing threat status of marine organisms. We organize the methods according to the availability of data on the natural history, ecology and population biology of species. There are three general approaches to inferring or assessing extinction risk: (i) correlative approaches based on knowledge of life histories and ecology; (ii) time-series approaches that examine changes in abundance; and (iii) demographic approaches based on age- or stage-based schedules of vital rates and fisheries reference points. Many methods are well suited to species that are highly catchable and/or have relatively low productivity, but theory is less well developed for assessing extinction risk in species exhibiting narrow geographical distributions or ecological specialization. There is considerable variation in both definitions of extinction risk and the precision and defensibility of the available risk assessment methods, so we suggest a two-tiered approach for defining and assessing extinction risk. First, simple methods requiring a few easily estimated parameters are used to triage or rapidly assess large numbers of populations and species to identify potentially vulnerable populations or species. Second, the populations and species identified as vulnerable by this process can then be subject to more detailed and rigorous population analysis explicitly considering sources of error and uncertainty.
\end{abstract}

Keywords CITES, fish, IUCN Red List, life history, reference points, threat

\author{
Correspondence: \\ Nicholas K. Dulvy, \\ Centre for Environ- \\ ment, Fisheries and \\ Aquaculture Science, \\ Lowestoft Laboratory, \\ Pakefield Road, \\ Lowestoft, Suffolk \\ NR3 3 OHT, UK \\ Tel.: 44-1502-562244 \\ Fax: 44-1502-513865 \\ E-mail: n.k.dulvy@ \\ cefas.co.uk
}

Received 8 Dec 2003

Accepted 21 June 2004

Introduction $\quad 256$

Defining extinction $\quad 257$

$\begin{array}{ll}\text { The routes to extinction in the sea } & 258\end{array}$

Life history and 'rule of thumb' approaches $\quad 258$

$\begin{array}{lr}\text { Estimating population parameters } & 259\end{array}$

using life-history invariants

Life-history benchmarks

$\begin{array}{lr}\text { Qualitative ranking using threat correlates } & 259\end{array}$ 


$\begin{array}{ll}\text { Time-series approaches } & \mathbf{2 6 0} \\ \text { The population growth rate } & 260 \\ \text { Sighting frequency } & 261 \\ \text { Population projection } & 262 \\ \text { Diffusion approximation } & 262 \\ \text { Decline rates } & 263 \\ \text { Demographic approaches } & \mathbf{2 6 5} \\ \text { Potential jeopardy level } & 265 \\ \text { Rebound potentials } & 265 \\ \text { Life-cycle analysis } & 266 \\ \text { Reference points } & 267 \\ \text { Discussion } & \mathbf{2 6 8} \\ \text { Assumptions } & 268 \\ \text { Methodological gaps } & 268 \\ \text { Geographical range size } & 268 \\ \text { Ecological specialisation } & 269 \\ \text { Minimum viable population size } & 269 \\ \text { Comparability of threat criteria } & 270 \\ \text { Conclusion } & \mathbf{2 7 1} \\ \text { Acknowledgements } & \mathbf{2 7 1} \\ \text { References } & \mathbf{2 7 1}\end{array}$

\section{Introduction}

Severe habitat loss and population declines of species have occurred in the oceans, leading to concerns that populations or species may be at risk of extinction over large spatial scales (Roberts and Hawkins 1999; Dulvy et al. 2003). A number of marine species have been inferred to have disappeared from relatively large discrete units of their overall geographical range (Carlton et al. 1999; Dulvy et al. 2003). Two or possibly three species of skate (Rajidae) and an angel shark (Squatina squatina, Squatinidae) are locally extinct over part of their former range in the Irish Sea (Rogers and Ellis 2000; Dulvy et al. 2003). The smalltooth sawfish (Pristis pectinata, Pristidae) is locally extinct from Bermuda and regionally extinct from the western Atlantic (Smith-Vaniz et al. 1999; Anonymous 2000; Musick et al. 2000). The giant yellow croaker (Bahabia taipingensis, Scianidae) was endemic to coastal China; but now is rarely captured throughout its known range despite continued targeted fishing effort (Sadovy and Cheung 2003). The barndoor skate (Dipturus laevis, Rajidae) also has a small range for a marine fish and has declined substantially throughout a large part of its NW Atlantic range, particularly along the continental shelf (Casey and Myers 1998).
A number of commercially important species were included in the World Conservation Union (IUCN) Red List of Threatened Animals (Hudson and Mace 1996; IUCN 1996; Mace and Hudson 1999). These fishes, including Atlantic cod (Gadus morhua, Gadidae), southern bluefin tuna (Thunnus maccoyii, Scombridae) and Atlantic halibut (Hippoglossus hippoglossus, Pleuronectidae), had undergone declines in abundance at the qualifying rate over a period of time equivalent to at least the length of three generations.

The listing of fishes and other marine organisms under the IUCN Red List scheme and increasing concerns for the broader negative impacts of exploitation on marine biodiversity and ecosystem function have brought conservation issues to the forefront of fisheries science (Jennings and Kaiser 1998; Roberts and Hawkins 1999; Reynolds et al. 2002; Roberts 2003). International signatories of the Johannesburg Declaration on Sustainable Development are committed to achieving a significant reduction in the rate of biodiversity loss by 2010 (WSSD 2002). An important component for meeting this commitment involves the identification and protection of potentially endangered species. Typically, this has been performed using various threat-listing protocols, such as those used by the 
Convention on International Trade in Endangered Species of Wild Flora and Fauna (CITES) and the IUCN, which were originally developed to describe risk in terrestrial species, particularly mammals and birds. Only recently have these threat-listing protocols been applied to marine species (e.g. IUCN 1996). This has resulted in considerable discussion and some disagreement over their validity and utility (Mace and Hudson 1999; Matsuda et al. 2000; Powles et al. 2000; Reynolds et al. 2001, 2002; Dulvy et al. 2003).

Here we provide an overview of methods of assessing vulnerability as applied to marine fishes derived mainly from the fisheries dynamics and conservation biology literature. We first outline operational definitions of extinction and the possible routes to extinction. Then we provide an overview of both qualitative and quantitative methods that have been proposed for assessing vulnerability in fishes. We conclude by highlighting key assumptions of the methods and some unresolved issues.

\section{Defining extinction}

Strictly, extinction is defined as the point at which the last member of a species has died out (Purvis et al. 2000b). This raises two questions: (i) what is a species, (ii) what is the objective for assessing extinction risk? Here we assume there is a consensus on the integrity and definition of the species in question.

The key to how stringent we need to be in our definition of extinction depends on the objectives for assessing extinction risk or threat listing. If a twotier approach is taken to assessing threat or extinction risk, then a more relaxed definition can be used when the objective is to rapidly assess the relative threat status or extinction risk status across a large number of populations or species. A more stringent definition of extinction risk can be considered if the objective is to assess the absolute level of threat status or extinction risk. This more formal and absolute definition would be more appropriate, for example, if the risk assessment is going to trigger strong protection measures and corresponding political, economic and societal sacrifices. Below we summarize the various available definitions in descending order of stringency.

There is a practical difficulty of measuring the point at which the taxon has become extinct, particularly in the sea (Roberts and Hawkins 1999; Purvis et al. 2000b; Dulvy et al. 2003). For example, a species is defined as 'Extinct in the Wild' by IUCN Red List criteria when exhaustive surveys in known and/or expected habitat, at appropriate times (diurnal, seasonal, annual) throughout its historic range have failed to record an individual (Hilton-Taylor 2000). Other methods of threat assessment either have a similarly stringent definition (OSPAR, COSEWIC, Endangered Species Act, USA) or leave the term undefined (CITES, Bern Convention, Wildlife and Countryside Act, UK). The best evidence on recent extinctions comes from birds and mammals over the last 500 years, although even these data are considered incomplete (Groombridge and Jenkins 2000; Purvis et al. 2000b).

To achieve a more general operational measure of extinction requires the relaxation of this stringent definition of extinction by varying degrees. One approach is to use threat-listing categories (e.g. IUCN, American Fisheries Society) and assume species are classified with equal effort and rigour and that the decline thresholds and criteria provide an accurate assessment of true extinction (Mace 1995; Purvis et al. 2000a,b). Assessments of the global threat status of all bird species have been completed (IUCN 2001), and mammals and amphibians will be finished within about 2 years of the time of writing. Such an approach might be suitable for these taxa, but few marine organisms (e.g. $<5 \%$ of fishes) have been assessed using threat criteria. Fishes have been assessed non-randomly according to taxonomic group, location and in some cases, expected degree of endangerment. An exception is in the USA and Canada where all marine fishes were assessed consistently using the American Fisheries Society criteria (Musick 1999; Musick et al. 2000).

Another approach to measuring extinction risk is to assume that a small-scale extinction is a step towards global scale extinction (Pitcher 2001; Dulvy et al. 2003). The least stringent approach has been to determine 'vulnerability' as a population's response to a forcing factor, e.g. exploitation. The most widely used metric for marine organisms has been the rate of decline over temporal and/or spatial gradients of exploitation (Jennings et al. 1998, 1999; Dulvy et al. 2000; Reynolds et al. 2001; Baum et al. 2003). This can be measured as the slope parameter of a model fit or calculated as the per cent change in abundance over time. While this metric of 'vulnerability' is the least stringent definition of extinction risk, it has at least allowed the development of various generalities, such as 
linking life histories to decline (Reynolds et al. 2001; Reynolds 2003).

\section{The routes to extinction in the sea}

There are two major causes of local and regional scale extinctions in the sea. Exploitation and habitat destruction have been attributed as the primary causes in 55 and $37 \%$ of the 133 documented local, regional and global scale marine extinctions (Dulvy et al. 2003). The cause of the other local, regional and global scale extinctions was attributed to invasive species, climate change, pollution and disease.

Exploitation has caused disappearance of both target and bycatch species. Target species that have disappeared at local, regional or global scales include Steller's sea cow (Hydrodamalis gigas, Dugongidae), the great auk (Alca impennis, Alcidae), the Icelandic spring-spawning herring stock (Clupea harengus, Clupeidae), the white abalone (Haliotus sorenseni, Haliotidae), and the giant yellow croaker (B. taipingensis) (Beverton 1990; Tegner et al. 1996; Carlton et al. 1999; Sadovy and Cheung 2003). All of these species have (or had) relatively small geographical ranges and high 'catchability', i.e. a large fraction of the population was vulnerable to exploitation. In addition, some of these species may have been intrinsically vulnerable to exploitation because of their large body sizes, slow growth, late maturation and low population growth rate. Examples of bycatch species that have disappeared include common skate (D. batis), white skate (Rostroraja alba, Rajidae) and angel shark (S. squatina) from the Irish Sea and parts of the Mediterranean (Brander 1981; Aldebert 1997; Rogers and Ellis 2000; Jukic-Peladic et al. 2001). Such species are large bodied and found in habitats favoured by more valuable targeted species and within the reach of fishing gears, such as trawls and long-lines.

Habitat loss is implicated in the local extinction of the dwarf frogfish (Antennarius pauciradiatus, Antennariidae), and bigtooth cardinalfish (Apogon affinis, Apogonidae) from Bermuda; the deep-snouted pipefish (Syngnathus typhle, Syngnathidae) and fifteen-spined stickleback (Spinachia spinachia, Gasterosteidae) from the Wadden Sea; the harlequin leatherjacket (Oxymonacanthus longirostris, Monacanthidae) from Okinawa, Japan; and the Galapagos damselfish (Azurina eupalama, Pomacentridae) (Smith-Vaniz et al. 1999; Hawkins et al. 2000;
Wolff 2000). Most of these species exhibit some form of ecological specialization such as low larval dispersal capacity with unusual reproductive modes (the mouth brooding cardinal fish and the parental caring pipefish and stickleback) or limited diet (the leatherjacket is an obligate coral feeder). The exception is the Galapagos damselfish, which appears to be a typical pomacentrid planktivore. However, in contrast to many other pomacentrid species, the Galapagos damselfish had a small geographical range. A large proportion of coral reef fishes with relatively restricted geographical ranges (55\%) qualify as threatened under IUCN Red List criteria (Hawkins et al. 2000).

The intrinsic factors or correlates underlying the major routes to local, regional and global scale extinction in the sea appear to be large body size, small geographical range and ecological specialization. The key extrinsic factor appears to be a high degree of exposure to a causal factor, i.e. high catchability for exploited species. These patterns are broadly similar to the main correlates of global scale freshwater and terrestrial extinctions (McKinney 1997; Reynolds 2003).

\section{Life history and 'rule of thumb' approaches}

Life histories underpin demography and population dynamics and therefore determine intrinsic vulnerability to decline, recovery potential and ultimately extinction risk (Hutchings 2001c; Jennings 2001; Reynolds et al. 2001; Hutchings 2002). Environmental and ecological factors such as food supply, predation risk and abiotic factors influence age-specific probabilities of survival, growth and fecundity (Hutchings 2002). However, any individual can only acquire and store a finite amount of energy and allocation of this energy is constrained by trade-offs; where fitness-enhancing changes in one trait will be countered by changes in another (Reynolds et al. 2001; Hutchings 2002). As a result, long-lived species grow slowly, have late maturity and attain large body sizes whereas short-lived species grow quickly, mature early and have smaller body sizes (Beverton 1963, 1992; Charnov 1993; Cortés 2000; Rochet 2000; Reynolds et al. 2001). Most fishes grow throughout their lives and tend to mature at a fixed proportion of their maximum age or length (Jensen 1997). Consequently, long-lived species have longer reproductive spans and lower annual reproductive output (Jennings and Beverton 1991; 
Denney et al. 2002). Slow life histories are linked to low maximum rates of population growth and consequently species exhibiting such life histories are intrinsically more vulnerable to exploitation and have less capacity to recover from exploitation (Hutchings 2001a; Reynolds et al. 2001, 2002; Hutchings and Reynolds 2004).

\section{Estimating population parameters using life-history} invariants

Population parameters such as body growth rate, age at maturity and natural mortality are key elements of the methods outlined in this review. Constant or invariant relationships among life-history traits can be used to estimate missing trait values where little detail is known of population biology. The invariants are near-constant ratios among life-history parameters such as the relationships between natural mortality $M$, and the von Bertalanffy growth parameter $k, M / k=1.7$ in teleosts (Charnov 1993); length at maturity $L_{\alpha}$, and asymptotic length $L_{\propto}, L_{\alpha} / L_{\propto}=$ 0.66 (teleosts) and 0.73 (elasmobranchs) (Charnov 1993; Jensen 1997; Frisk et al. 2001); age at maturity $\alpha$, to maximum age $T_{\max }, \alpha / T_{\max }=0.6$ (elasmobranchs) (Frisk et al. 2001); age at maturity $\alpha$ to mortality rate $M, \alpha M \sim 2$ (Charnov 1993); and, for sex-changing species, the ratio of length at sex change $L_{50}$, to maximum length $L_{\propto}, L_{50} / L_{\propto}=0.72$ (Allsop and West 2003). Life-history traits can also be estimated from statistical correlations derived from larger comparative studies (Pauly 1980; Froese and Binohlan 2000). For example, body growth rate, $k$ is negatively related to maximum theoretical body size, measured as asymptotic length $L_{\propto}$, or weight $W_{\propto}$ (Pauly 1998). Natural mortality must approximate the reciprocal of lifespan, but other simple empirical equations have been derived from cross-species comparative analyses (Pauly 1980; Hoenig 1983; Charnov 1993; Froese and Palomares 2000). Phylogenetically independent analyses can remove bias, noise and lack of statistical independence that occur in simple cross-species analyses by incorporating relatedness among taxa (Rickman et al. 2000; Reynolds et al. 2001; Freckleton 2002). When using parameters derived from these approaches it should be borne in mind that there will be interpopulation variation around the species average. Fishes exhibit a high degree of phenotypic plasticity, and geographical variation in life histories, which is overlooked by the methods used to estimate life-history parameters (Roff 1992; Atkinson 1994; Hutchings 2002). In addition, exploitation may result in genotypic evolution and changes in life-history traits (Nielsen and Kenchington 2001; Olsen et al. 2004).

\section{Life-history benchmarks}

There is a continuum of life-history patterns and therefore vulnerabilities, ranging from slow life history/high vulnerability to fast life history/low vulnerability. We know that large fishes such as sharks and rays are more vulnerable, but it would be useful to have some benchmarks beyond which species could be classified as threatened or at risk. One approach to determining such a benchmark is to use species that have already become locally or regionally extinct. It may then be assumed that other species with similar life histories and subject to similar levels of extrinsic threat (e.g. exploitation) are also likely to become locally or regionally extinct. This approach has been used to categorize extinction risk in skates (Rajidae) using the barndoor skate (D. laevis) as a body size benchmark (Dulvy and Reynolds 2002). The approach identified 10 additional skate species; including three species that had exhibited local scale extinctions and the smooth skate (Dipturus innominatus, Rajidae), which is endemic to New Zealand. The highlighting of the smooth skate using this approach was used to justify further research and monitoring by fisheries scientists, who had been concerned about its vulnerability (Francis et al. 2001).

\section{Qualitative ranking using threat correlates}

Qualitative measures of the biological and ecological characteristics of species can be used to rank species vulnerabilities to a known threat. The biological and ecological attributes of species are scored categorically and summarized to produce two metrics: their susceptibility to a known threat, such as mortality from a fishing gear, and their intrinsic capacity to recover after depletion (the maximum rate of population increase). Species are ranked as least sustainable if they exhibit both a high susceptibility rank and a low recovery rank. This approach was developed to determine the relative sustainability of a diverse array of bycatch species in a North Australian prawn fishery (Stobutzki et al. 2001). Prawn trawls operate close to the seafloor, hence demersal and benthic species were scored more highly for susceptibility than pelagic species. Other susceptibility criteria included: preferred habitat, survival of bycatch, geographical range overlap, 
day/night catchability, diet and depth range. Six recovery criteria were used: probability of breeding, maximum size, removal rate, parental investment (e.g. broadcast spawning vs. live-bearing and parental care), hermaphroditism and a mortality index (Stobutzki et al. 2001). This approach is highly promising for data-poor situations, such as newly developed fisheries in areas of high species richness.

In summary, life-history invariants and empirical equations derived from comparative analyses can be used to estimate important population parameters that are the basis of extinction risk assessment. There are known links between life-history traits and vulnerability that can be used alone, or combined with distributional and behavioural information, to qualitatively rank species vulnerabilities.

\section{Time-series approaches}

\section{The population growth rate}

Population growth rate, $\lambda$, is the actual rate at which population size changes each year

$\lambda=N_{t+1} / N_{t}$

where $\lambda$ is referred to as the 'finite growth rate'. At low population sizes there is no density-dependent regulation of population growth and in these circumstances $\ln \lambda$ is referred to as the maximum population growth rate $\left(r_{\max }\right)$.

The finite population growth rate $\left(\lambda=\mathrm{e}^{r}\right)$ can be estimated as the slope of a linear regression of abundance this year vs. abundance the previous year (Fagan et al. 2001; Rochet and Trenkel 2003).

$\ln N_{t}=a+r N_{t-1}$

Although very short time series have sometimes been used, we recommend the use of time series of 15 years or longer. This method can produce poor estimates of $r$, unless the population trend is consistently negative or positive year-on-year. We recommend that the resultant estimate of $r$ be checked before use by simulation.

There are also more data intensive approaches to estimating $r$ based on the spawner-recruit (S-R) relationship. The slope at the origin of the $\mathrm{S}-\mathrm{R}$ relationship represents the maximum rate of recruit production per kilogram of spawners, $\alpha$. This can be used to approximate $r_{\max }$ because it is the theoretical maximum population growth rate in the absence of density dependence. This parameter can be estimated using the Ricker, Beverton-Holt and hockey stick S-R models, with the Ricker model generally providing a more conservative estimate (Cook 1998; Myers et al. 1999; Myers 2001). S-R models assume constant, equilibrium conditions. However, there is increasing evidence that $S-R$ relationships vary with environmental regime (O'Brien et al. 2000; Clark and Hare 2002) and are typically derived from virtual population analysis of multiple data sources (e.g. mortality and maturity schedules, numbers-at-age, weightat-age), each of which is subject to measurement error. Consequently, S-R relationships can have considerable variances, and the parameter estimates are subject to a high degree of uncertainty (Walters and Ludwig 1981; Myers 2001). The slope at the origin is standardized to the number of spawners produced per spawner per lifetime $\hat{\alpha}$ :

$\hat{\alpha}=\alpha \cdot \operatorname{SPR}_{F=0}$

where $\mathrm{SPR}_{F=0}$ is the maximum spawning biomass resulting from each recruit when fishing mortality, $F=0$ (Gabriel et al. 1989; Mace and Sissenwine 1993; Myers et al. 1997, 1999). This is then standardized to the number of spawners produced per spawner each year $\tilde{\alpha}$ :

$\tilde{\alpha}=\hat{\alpha}\left(1-p_{\mathrm{s}}\right)=\alpha \cdot \operatorname{SPR}_{F=0}\left(1-p_{\mathrm{s}}\right)$

where $p_{\mathrm{s}}$ is adult survival that corresponds to natural mortality by $p_{\mathrm{s}}=\mathrm{e}^{-M}$. Both recruit production $\hat{\alpha}$, and spawner production $\tilde{\alpha}$, are related to lifehistory traits and appear to be suitable proxies for the maximum rate of population increase (Myers et al. 1997, 1999; Myers 2001; Denney et al. 2002). Having calculated $\tilde{\alpha}$, the maximum rate of population increase $r_{\max }$ can be calculated iteratively for an age-structured population as

$\left(\mathrm{e}^{r_{\max }}\right)^{a}-p_{\mathrm{s}}\left(\mathrm{e}^{r_{\max }}\right)^{a-1}-\tilde{\alpha}=0$

where $a$ is age at maturity (Myers et al. 1997).

The population growth rate can be used as a measure of the replacement rate or potential recovery rate and thus can be used to rank species according to their intrinsic vulnerability to exploitation. Stocks tend to decline more than expected in response to exploitation when they have low potential rates of populations increase, and high ages of maturity and large maximum size (Jennings et al. 1998). Both recruit $(\alpha)$ and adult production $(\tilde{\alpha})$ are negatively related to maximum body size, and age at maturity and fecundity, and positively related to body growth rates in broadcast spawning teleosts (Denney et al. 2002). 


\section{Sighting frequency}

For very rare species, the probability that local scale extinction has occurred can be calculated using a time series of incidental observations, such as strandings, a series of museum collections or records of entrapment rates on power station water intake screens (Solow 1993a,b; Reed 1996). The probability that local extinction has occurred follows a stationary Poisson process:

$p=1-\left(\frac{t_{c}}{T}\right)^{n}$

where the number of time intervals in which the species was observed is $n$, the total number of intervals sampled is $T$, and the number of intervals up to the time the species was last observed is $t_{c}$ (Solow 1993a,b; Burgman et al. 1995; Grogan and Boreman 1998). A second method accounts for the number of individuals observed in the period prior to the last sighting. The probability that a species is locally extinct becomes

$p=1-\left(\frac{t_{c}}{T}\right)^{k}$

where $k$ is the total number of individuals observed among $t_{c}$ time intervals over a total number of intervals, T (Burgman et al. 1995; Grogan and Boreman 1998). Sensitivity analyses have been used to suggest minimum probability levels of $p=0.75$ for declaring a species to be in danger of local extinction and $p=0.95$ for locally extinct (Grogan and Boreman 1998). The important assumption is that observations of species represent a stationary Poisson process, i.e. that the average chance of incidentally collecting or observing a species does not change over time. Therefore, systematic or targeted collections or surveys for a species would violate the underlying assumptions of this approach (Solow 1993a). The method is most appropriate for chronically small, stable population subject to rapid extinction (Solow 1993a).

These methods were applied to two data sets of incidental records of Atlantic sturgeon (i) from the James River, Virginia, USA and (ii) captures or strandings reported to the UK Marine Fish Recording Scheme up to 2003 (Table 1). James River Atlantic sturgeon were captured incidentally in the annual Virginia Institute of Marine Science trawl survey (Grogan and Boreman 1998). The survey ran from 1964 to 1994 , hence $T=31$. A total of $k=25$ individual sturgeon were
Table 1 Incidental records of Atlantic sturgeon (a) captured by the Virginia Institute of Marine Science 19641994 trawl survey of the James River, Virginia and (b) captures and strandings reported to UK Fish Recording Scheme up to 2002.

\begin{tabular}{lll}
\hline & \multicolumn{2}{l}{ Number of individuals captured } \\
\cline { 2 - 3 } Year & Survey A & Survey B \\
& & \\
\hline & & \\
1869 & - & 1 \\
1954 & - & 1 \\
1956 & - & 1 \\
1964 & 1 & - \\
1972 & 3 & - \\
1975 & 1 & - \\
1978 & 2 & - \\
1979 & 7 & - \\
1980 & 4 & - \\
1981 & 5 & - \\
1982 & 1 & 1 \\
1989 & 1 & - \\
1998 & - & 1 \\
1999 & - & 1 \\
2001 & - & 1 \\
Sum & 25 & 7 \\
$p$ (Equation 1) & 0.855 & 0.051 \\
$p$ (Equation 2) & 0.995 & \\
\hline & & \\
\hline & & \\
& &
\end{tabular}

incidentally captured in $n=9$ years and the last sturgeon was captured in the 25th year of the survey $\left(t_{c}=25\right)$ duration. We analysed records compiled by the UK Marine Fish Recording Scheme, which databases historic and current records of marine fishes reported by commercial fishers, fish merchants, sea anglers, divers, yachtsmen and the general public. The sturgeon records began in 1869 spanning the years up to 2002 when the records were extracted from the database $(T=134)$. A total of $k=7$ individuals were recorded in $n=7$ years and the last sturgeon was recorded in the 133rd year of the record span $\left(t_{c}=133\right)$. The probabilities that sturgeon are locally extinct from the James River are 0.856 and 0.995 for Equations 1 and 2 respectively, and for UK waters the probabilities from both equations are the same $(p=0.051)$. The UK data may not meet the assumptions of this method as the database was set up in 1998 and the resultant publicity may have increased the probability of reporting a sturgeon capture. The probability of local extinction for UK sturgeon derived with these methods is low, which is surprising given the 
independent evidence that this population may be close to regional extinction (ICES 2003b), the relatively low number of sturgeon reported in the UK data set (seven individuals), the larger time span and the potentially larger geographical sample area compared with the James River. This highlights a key problem of this method; it is particularly sensitive to $t_{c}$, i.e. incidental records which occur later in the record series (Grogan and Boreman 1998; Roberts and Solow 2003). Additional methods are available for declining populations (Solow 1993b).

\section{Population projection}

The rate of population change can be estimated from a time series and can be used to project forward to estimate future population size (e.g. Matsuda et al. 1998). The rate of population change $r_{t}$ is calculated as

$r_{t}=\ln \left(N_{t+1} / N_{t}\right)$

where $N_{t}$ is the number of mature individuals in year $t$. Under the assumption that $r_{t}$ is an independent variable which reflects the probability distribution in each year, then a value for $r_{t}$ can be selected to project the current population forwards using $N_{t+1}=N_{t} \exp \left(r_{t}\right)$. Similar to Equation 2 , this method can also produce poor estimates of $r$, and we suggest the estimate of $r$ is checked by simulation before use. This approach has been used to assess the probability of global extinction of the southern bluefin tuna (T. maccoyi). A 30-year time series of adult numbers was used to provide 29 estimates of $r_{t}$ which were used to simulate 1000 replicate 100-year population projections (Matsuda et al. 1998). The population was assumed to be quasi-extinct if there were fewer than 500 individuals remaining in any replicate. This occurred in 960 of 1000 simulations resulting in an extinction probability of $96 \%$ over a 100 -year period. This approach is highly dependent on the quality of the estimates of $r$.

\section{Diffusion approximation}

This approach is based on the assumption that stochastic age-structured population models without density dependence behave as a stochastic discrete time model with exponential growth or decline (Dennis et al. 1991). The number of adults at time $t+1$ can be written as:
$N_{t+1}=N_{t} \exp \left(\mu_{t}+\varepsilon\right)$

where $\varepsilon$ is a function of time, drawn from a normal distribution with a mean of zero and a variance, $\sigma^{2}$. The parameter $\mu$ is the rate of population increase or decrease through time, and $\sigma$ is the population variability. When censuses are conducted annually and there are no missing census points, the maximum likelihood estimates of $\mu$ and $\sigma^{2}$ are:

$\mu=\operatorname{mean}\left[\ln \left(N_{t+1} / N_{t}\right)\right]$

$\sigma^{2}=\operatorname{var}\left[\ln \left(N_{t+1} / N_{t}\right)\right]$

These parameters can be used to estimate risk metrics such as the long-term population trend, extinction probabilities and time to extinction (Dennis et al. 1991). The long-term population trend is described by the mean rate of population growth, which is calculated as:

$\lambda=\exp \left(\mu+\left(\sigma^{2} / 2\right)\right)$

The probability of declining from the most recent population size $n_{q}$ to a lower threshold population size $n_{e}$ (e.g. one remaining individual, or $90 \%$ decline, i.e. $10 \%$ of $n_{q}$ ), is calculated as:

$\pi=\left(n_{e} / n_{q}\right)^{2 \mu / \sigma 2}$

The time to extinction $\theta$, is calculated as:

$\theta=\ln \left(n_{e} / n_{q}\right) / \mu$

The Dennis et al. (1991) model is appealing because it is analytically tractable and requires data that are relatively simple to acquire. However, it does not incorporate stochasticity or density dependence and is highly sensitive to sampling error (Holmes 2001).

True population estimates are rarely available for marine organisms, whereas counts of a particular age class or stage are more readily available, e.g. number of spawning salmon. One option is to assume that such data have the same statistical properties as total population counts and substitute, $A_{t}$, the age or stage-specific count at time $t$ in place of $N_{t}$ in Equation (9). A more appropriate and unbiased method is to calculate a running sum of $A_{t}$ over a number of census estimates to obtain a count that more closely approximates the total population:

$R_{t}=\sum_{i=1}^{L} w_{i} \cdot A_{t-1}$

where $L$ is the number of census counts added to give a running sum at time $t$ and $w_{i}$ is the weight 
given to each count. Ideally the optimal transformation would use survival and fecundity to calculate $w_{i}$ and $L$, but where such information is limited, a weighting of $w_{i}=1$ can be used for all. Where possible, $L$ should approximate the generation time of the organism; however the length of the time series will constrain L, e.g. 15-20 years of data seem to be a minimum for $L=4$ (Holmes 2001). The running sums can be used directly as a surrogate for population counts but this results in biased estimates. A more robust approach is to use regression slopes of the mean or variance in running sums over time:

$\mu=$ slope of the regression of mean

$\left[\ln \left(N_{t+1} / N_{t}\right)\right]$ vs. time

$\sigma^{2}=$ slope of the regression of variance $\left[\ln \left(N_{t+1} / N_{t}\right)\right]$ vs. time

Simulations suggest that the slopes approach is less biased than the direct or running sums methods as it is relatively insensitive to sampling error and the choice of $L$, at the expense or providing a more variable estimate of variance (Holmes 2001).

Once the parameters have been estimated, extinction risk metrics can be calculated such as the mean rate of population growth and the probability of $90 \%$ decline within a given time horizon (Equations 12 and 13) (Holmes 2001). Time to extinction (Equation 14) cannot be calculated using the parameters estimated with the running sum and slope methods because this requires an estimate of total population size.

The diffusion approximation methods have been used in population viability analyses of threatened terrestrial species but to the best of our knowledge have not been applied to marine species. They do not incorporate density dependence or stochasticity and consequently are highly deterministic and assume that the variance over time is intrinsic to the population, rather than a sampling error and they also assume that the conditions underlying historical trends will also be constant over the future time scale of the predictions.

\section{Decline rates}

The most widely used method of assessing extinction risk involves some measure of decline in adult abundance over time. This approach is used by international and regional conventions and organisations, e.g. CITES, IUCN Red List of threatened species, Convention on the conservation of European wildlife and natural habitats 'Bern Convention'. It has also been incorporated assessments that feed into national legislation, such as the Wildlife and Countryside Act of 1981 in Great Britain and the Species at Risk Act in Canada.

Our understanding of extinction risk is greatest for small populations, which are more likely to become extinct than large populations because of greater influence of environmental and demographic stochasticity - the 'small population paradigm' (Caughley 1994; Simberloff 1998; Sæther and Engen 2003). As a consequence, threat criteria based on the small-population paradigm tend to be considerably more detailed. However the populations may be considered particularly at risk if they show, or are expected to show, evidence of a decline - the declining-population paradigm (Caughley 1994; Mace and Hudson 1999). In small pelagic fishes the most severe declines have been followed by the slowest recovery (Beverton 1990). This is consistent with the suggestion that increased risk of extinction is associated with reduced probability of recovering to former levels of abundance (Hutchings 2000, 2001a). The declining-population paradigm may have a poorer theoretical underpinning, but it is intuitively appealing and generally more relevant to practical conservation problems (Mace and Lande 1991; Hendrick et al. 1996; Mace and Hudson 1999). While decline rate is related to non-recovery, there is a lack of consensus on whether decline rate reflects extinction risk (Hutchings and Reynolds 2004). The median maximum population decline among 232 marine fish populations was $83 \%$ (Hutchings and Reynolds 2004), among all of these declines there has only been one possible example of a marine extinction which was preceded by a steep decline rate - the disappearance of the Icelandic spring-spawning herring population (Jakobsson 1980; Beverton 1990). In addition, there are a number of populations which have exhibited rapid recovery following decline, particularly clupeiod populations (Hutchings 2001c), although the observed recovery rates may be biased by continued fishing mortality and unaccounted for bycatch mortality.

The setting of decline thresholds in threat criteria is based on experience, primarily with terrestrial taxa, and extensive consultation, peer review and 
consensus building (e.g. Hudson and Mace 1996; Hilton-Taylor 2000). This can be perceived as a unsatisfactory basis for using decline rates to assess extinction risk when there may be high social, economic and political costs associated with fishery closures and other management measures.

A more general issue is what kind of conservation problem we are concerned about. The decline rate may or may not indicate a risk of extinction at the population level. At the ecosystem level, the decline of an abundant species may represent a massive biomass loss which may be of greater concern, e.g. for functionality, stability or resilience (Bellwood et al. 2003; Dulvy et al. 2004), than the loss of a small number of individuals of a rare species. On longer time scales, the viability of a population of a rare species may play an important role in allowing the marine ecosystem to adapt to environmental variation and climate change (Magurran and Henderson 2003). Decline criteria usually specify declines of $\geq 50-90 \%$ over a time period of more than 10 years or three generations (e.g. IUCN,
COSEWIC, AFS) or $\geq 50 \%$ decline in more than 5 years or two generations (CITES) to trigger threat listing (Table 2). Note that CITES does not present these values as a threshold, but as a guideline only. While it is recognized that decline criteria, such as those used by the IUCN, are effective at flagging rapid short-term population changes, in some circles they are thought to over-estimate extinction risk for many marine fish species (Matsuda et al. 1997; Musick 1998). However, one demographic study has found that IUCN decline criteria may actually underestimate extinction risk in longer lived species, such as sharks (Punt 2000). There is scope to test the degree to which decline rates and thresholds correspond with more detailed assessments of extinction risk (Matsuda et al. 1998) and also the degree to which decline rates and threshold correspond to fisheries management reference points (Smith et al. 1993; Punt 2000).

In summary, time series yield relative measures of vulnerability, such as population growth rate, and measures of the probability of extinction and time to

Table 2 Decline rates used in threat-listing criteria.

\begin{tabular}{|c|c|c|c|}
\hline Listing scheme & Decline rate (\%) & Time scale & Threat category \\
\hline \multirow[t]{2}{*}{ CITES } & $\geq 50^{\mathrm{a}}$ or & $\begin{array}{c}\text { Longer than } 5 \text { years } \\
\text { or two generations }\end{array}$ & Appendices I and II \\
\hline & $\geq 20^{\mathrm{a}}$ & $\begin{array}{l}\text { Longer than } 10 \text { years } \\
\text { of three generations }\end{array}$ & \\
\hline \multirow[t]{3}{*}{ IUCN } & $\geq 90^{b} \geq 80^{c}$ & $\begin{array}{r}\text { Longer than } 10 \text { years } \\
\text { or three generations }\end{array}$ & Critically endangered \\
\hline & $\geq 70^{b} \geq 50^{c}$ & $\begin{array}{r}\text { Longer than } 10 \text { years } \\
\text { or three generations }\end{array}$ & Endangered \\
\hline & $\geq 50^{b} \geq 30^{c}$ & $\begin{array}{l}\text { More than } 10 \text { years } \\
\text { or three generations }\end{array}$ & Vulnerable \\
\hline $\begin{array}{l}\text { Committee on the Status of } \\
\text { Endangered Wildlife in }\end{array}$ & $\geq 70^{b} \geq 50^{c}$ & $\begin{array}{l}\text { More than } 10 \text { years } \\
\text { or three generations }\end{array}$ & Endangered \\
\hline Canada (COSEWIC) & $\geq 50^{\mathrm{b}} \geq 30^{\mathrm{c}}$ & $\begin{array}{l}\text { More than } 10 \text { years } \\
\text { or three generations }\end{array}$ & Threatened \\
\hline \multirow[t]{4}{*}{ American Fisheries Society } & $\geq 99$ & $\begin{array}{l}\text { More than } 10 \text { years } \\
\text { or three generations }\end{array}$ & Vulnerable, high productivity species \\
\hline & $\geq 95$ & $\begin{array}{l}\text { More than } 10 \text { years } \\
\text { or three generations }\end{array}$ & Vulnerable, medium productivity species \\
\hline & $\geq 85$ & $\begin{array}{l}\text { More than } 10 \text { years } \\
\text { or three generations }\end{array}$ & Vulnerable, low productivity species \\
\hline & $\geq 70$ & $\begin{array}{l}\text { More than } 10 \text { years } \\
\text { or three generations }\end{array}$ & Vulnerable, very low productivity species \\
\hline
\end{tabular}

${ }^{a}$ Note that, 'these figures are presented only as examples because it is impossible to give numerical values that are applicable to all taxa. There will be many cases where these numerical guidelines do not apply. (Annex 5, Conference of the Parties Resolution 9.24)'. ${ }^{b}$ Where the causes of the reduction are clearly reversible AND understood AND ceased.

${ }^{c}$ Where the reduction or its causes may not have ceased OR may not be understood OR may not be reversible. 
extinction, e.g. diffusion approximation methods, depending on the duration of time series and its continuity. The decline thresholds of threat criteria are easily calculated using a wide variety of data and provide a useful way of comparing vulnerability across a wide array of species and may also provide an indication of reduced recovery rate, a possible surrogate of extinction risk.

\section{Demographic approaches}

\section{Potential jeopardy level}

Assessing vulnerability to exploitation requires estimates of the current fishing mortality rate $F$ and some measure of the capacity of the population to withstand that mortality. A simple method has been used to calculate the latter, the fishing mortality $F \varphi$, which will reduce the spawners produced per recruit $(\mathrm{SSB} / \mathrm{R})$ to below some arbitrary but safe 'jeopardy' level (Pope et al. 2000). The proposed level is $5 \%$ of the virgin SSB/R. This method utilizes the Beverton-Holt invariant $(h)$ which is the ratio of length at maturity/maximum asymptotic length $\left(L_{\alpha} / L_{\infty}\right)$, the von Bertalanffy growth coefficient $(k)$, maximum asymptotic length and weight parameters $\left(L_{\propto}, W_{\propto}\right)$, and natural and fishing mortality ( $M$ and F) (Beverton and Holt 1957; Beverton 1992; MacDonald et al. 1994; Pope et al. 2000). According to the Beverton-Holt yield equation, the cumulative lifetime biomass, $S S B$ of a year class of $R$ recruits which recruit at age $t_{r}$, are captured at age $t_{c}$ and mature at age $t_{\alpha}$ is:

$$
\begin{aligned}
\mathrm{SSB}= & R \cdot e\left[-M\left(t_{c}-t_{r}\right)-\mathrm{Z}\left(t_{\alpha}-t_{c}\right)\right] . \\
& a \cdot L_{\infty}^{3} \cdot \sum_{i=0}^{3} U_{i}\left[\frac{(1-h)^{i}}{1-e(-Z-i k)}\right] .
\end{aligned}
$$

The condition for fishing mortality to be at the jeopardy level, $F(\varphi)$ where $\varphi$ represents $5 \%$ SSB/R is:

$F(\varphi, 0.05)=\frac{e\left[-F_{\varphi}\left(t_{\alpha}-t_{c}\right)\right] \sum_{i=0}^{3} \frac{(1-h)^{i}}{1-e(-Z-i k)}}{\sum_{i=0}^{3}\left[\frac{(1-h)^{i}}{1-e(-M-i k)}\right]}$,

where the summation constant in the cubic expansion of the growth equation is $U_{i}=+1,-3,+3,-1$ for $n=0,1,2,3$, respectively. At present, the theory has only been developed for the situation where the age of capture is before age at maturation $t_{c}<t_{\alpha}$, but formulations are available for the more realistic case where mortality varies with length
(MacDonald et al. 1994). For non-target species or where data are limited, fishing mortality can be calculated using length cohort analysis (Jones 1981) or swept area methods (Pope et al. 2000). A general exploration of the link between life histories, exploitation pattern and the $F \varphi$ can be made by starting with a plausible range of growth rates and estimating the other parameters ( $h, M$ and $t_{\alpha}$ ) using the life-history invariant relationships described above. Species with slower body growth rates have lower natural mortality rates (Fig. 1a) and correspondingly higher ages at maturity (Fig. 1b). Species with faster growth rates have higher $F$ jeopardy levels; i.e. they can withstand higher levels of fishing mortality before declining to the jeopardy level of SSB/R (Fig. 1c). The later a fish is captured, with respect to its age of maturity, the greater the fishing mortality required to reduce the population to the jeopardy level of SSB/R. The general properties of this method have not been explored, but we suggest that it may be a useful way of determining the relative vulnerability of populations or species based on their life histories and exploitation patterns.

\section{Rebound potentials}

One approach to estimating vulnerability to decline is to calculate $r$ at a standardized population size. Smith et al. (1999) achieved this by calculating a rebound potential $r_{2 m}$, the growth rate at twice the natural mortality level. This equates to the point of maximum sustainable yield (MSY), which is assumed to be at half the virgin population size (Au and Smith 1997; Smith et al. 1999). This is calculated in three stages. First, $r$ is estimated using a modified version of the Euler-Lotka equation:

$\mathrm{e}^{-(M+r)}+l_{\alpha} b e^{-r \alpha}\left[1-\mathrm{e}^{-(M+r)(w-a+1)}\right]=1$

The five life-history parameters required are age at maturity $\alpha$, maximum reproductive age $w$, adult instantaneous natural mortality $M$, average number of female offspring per female $b$, and survival to age at maturity (pre-adult survival) $l_{\alpha}$. Pre-adult survival can be calculated from $l_{\alpha}=\mathrm{e}^{-M(w-a)}$ (Smith et al. 1999). Second, pre-adult survival is estimated at the point of MSY, i.e. where total mortality $\mathrm{Z}=$ $F+M=2 M$, where $F$ represents fishing mortality and $F=M$. If it can be assumed that this level of mortality is sustainable, then $r$ is set to zero and the new pre-adult survival $l_{\alpha, Z}$ can be calculated from: 
(a)
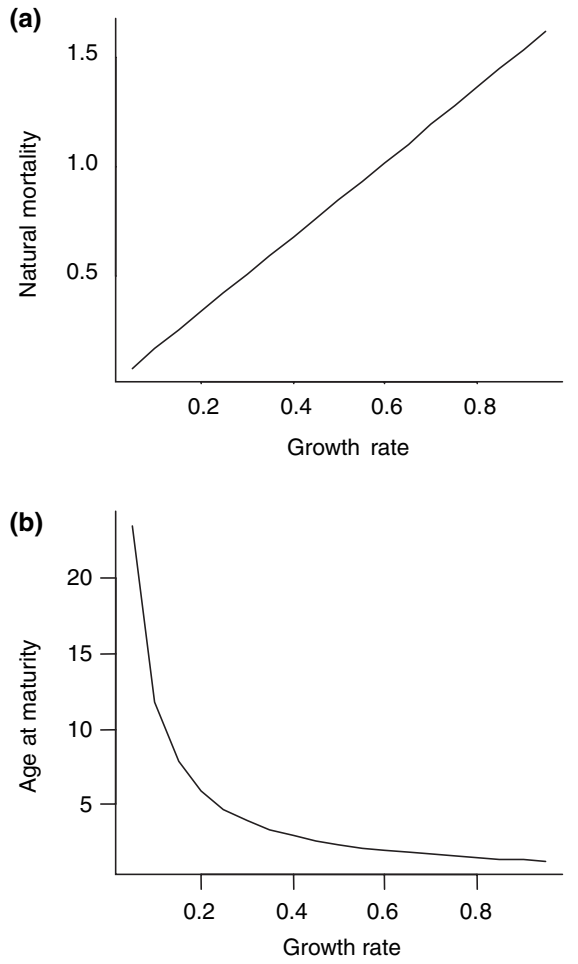

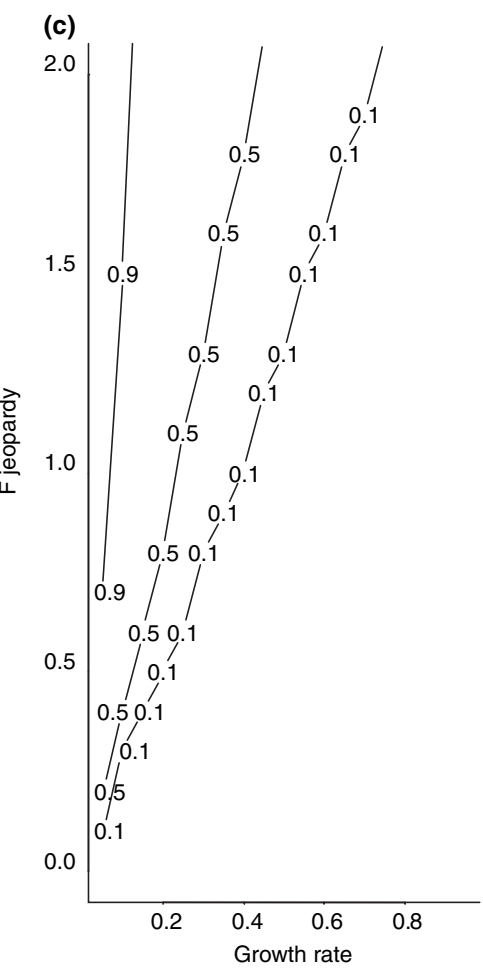

Figure 1 The relationship between life history, exploitation pattern and $F(\varphi)$, the fishing mortality required to reduce SSB/R to $5 \%$ of unexploited levels. (a) The relationship between the von Bertalanffy growth rate $k$, and the natural mortality rate, assuming the invariant relationship $M / k=1.7$. (b) The relationship between growth rate $k$, and the age of maturity $\alpha$, assuming the invariant relationship $\alpha M \sim 2$. (c) The relationship between growth rate $k$ and the fishing mortality $F \varphi$, which will reduce the spawners per recruit (SSB/R) to below $5 \%$, assuming an invariant relationship between length at maturity $L_{\alpha}$, and asymptotic length $L_{\propto}, L_{\alpha} / L_{\propto}=0.66$. The isopleths represent the age at capture $t_{c}$ expressed as a proportion of age of maturity $t_{\alpha}$. Three ratios are plotted here representing ages of capture $t_{c}$ at 10,50 and $90 \%$ of the age at maturity $t_{\alpha}$.

$\mathrm{e}^{-Z}+l_{\alpha, Z^{b}}\left[1-\mathrm{e}^{-Z(w-a+1)}\right]=1$

Third, the rebound level of population change $r_{z}$ is determined by removing fishing mortality, i.e. $\mathrm{Z}=M$. In practice, $r_{z}$ is calculated by inserting the new pre-adult survival $l_{\alpha, Z}$ into Equation (20) (Smith et al. 1999). Parameters can be derived from the literature and maximum reproductive age, $w$ can be assumed to approximate maximum age; natural mortality $M$ approximates 1/lifespan; average number of female offspring per female $b$ is estimated as annual fecundity divided by 2 .

This method was used to estimate rebound potentials for a relatively data-poor assemblage of 26 Pacific shark species. Rebound potentials were correlated with life-history traits, species with low rebound potential mature later and tend to be larger in size (Smith et al. 1999; Stevens et al. 2000). This suggests that low rebound potentials may provide a relative indication of extinction risk in comparisons across a number of species. This method may be more appropriate for relatively long-lived species than short-lived species because of the difficulty of estimating pre-adult survival for highly fecund fishes, which exhibit extremely high mortality in the first few weeks of life.

\section{Life-cycle analysis}

The life cycle of organisms can be summarized as schedules of the vital rates (growth, survival and reproductive output) that can be split according to age or stage classes (Caswell 1989). The population growth rate, $\lambda=\mathrm{e}^{r}$, is the integration of these vital rates over all ages or stages. If data on age- or stagespecific vital rates are available, this is a superior method of calculating the population growth rate compared with the correlative methods outlined 
earlier. However, age schedules of vital rates for marine organisms are rarely available, because it is difficult to estimate the age of individuals, or because the vital rates are themselves difficult to measure (Crouse et al. 1993). A less data-intensive approach that may be useful in marine conservation ecology is the use of stage-based models. The life history is divided into a number of significant life stages. For example, in a four-stage model $n_{1}-n_{4}$, the individuals in the three oldest classes reproduce at fertility rates $F_{2}, F_{3}$ and $F_{4}$ (elsewhere in this document $F$ represents fishing mortality) and have a probability $G_{x}$ of growing into the next size class, and a probability $P_{x}$ of remaining in the same size class. This approach can be used to calculate the population growth rate and also determine the most vulnerable age or stage in the life cycle, thereby allowing targeted management (Crouse et al. 1993; Benton and Grant 1999; Heppell et al. 1999, 2000; Cortés 2002). Both age- and stage-based methods are implemented in a similar manner using a system of equations to represent the change in abundance at each life stage in terms of the vital rates. This system of linear equations can be solved using matrix algebra as implemented using freely available software such as 'Poptools' (http://www. cse.csiro.au/poptools/matrices.htm). This basic approach can be used for population projection and was used to estimate future population sizes of the southern bluefin tuna (T. maccoyi) based on 12 age classes and incorporating variability in survival and reproductive rates as a normal random variable with a mean of 0 and standard deviation of 1 . The population was expected to decline to 1000 mature individuals by the year 2089 (Matsuda et al. 1998). A stochastic version of this approach has been used to explore the effect of pre- and post-maturation mortality on Atlantic cod population growth rate (Hutchings 2001b).

\section{Reference points}

Fisheries reference points are not strictly measures of extinction risk but they do provide well-studied limits to population reduction and hence boundaries of decline beyond which populations are thought to be at risk of irreversible collapse. Fishery scientists use quantitative models to provide management recommendations on suitable levels of exploitation; these are known as biological reference points (BRPs). There are two classes of reference point: a target reference point indicates 'the state of a fishery and/or resources that is considered desirable' whereas a limit reference point indicates 'the state of a fishery and/or resources that is considered undesirable' (Caddy and Mahon 1995; Garcia 1996).

In contrast to threat-listing criteria, the BRP used in fisheries management are expressed as either a fishing mortality rate $\left(F_{x}\right)$ or an absolute level of spawner biomass $\left(B_{x}\right)$. There are three common models that underlie a wide variety of BRPs including: production models, yield per recruit or 'dynamic pool' models and spawner per recruit models. These models are relatively data hungry.

Production models require a series of yield values from the fishery, measures of fishing effort and a measure of catchability $q$, to convert fishing effort into fishing mortality. They can provide two BRPs: $F_{\text {msy }}$ and $2 / 3 F_{\text {msy }}$. Parameters can be derived from a time series or spatially arrayed data whereby different fishing efforts in otherwise similar sites are used in place of a time series.

Yield per recruit models require estimates of individual growth and natural mortality rates and vulnerability to fishing. The models describe a dome-shaped or asymptotic relationship between fishing mortality, $F$ and the yield per recruit from which two BRPs have been found to be useful in fisheries management $\left(F_{\max }, F_{0.1}\right)$. However, the models do not account for the effect of fishing upon the proportion of mature fish and hence reproductive potential (Caddy and Mahon 1995).

Spawner per recruit models are the most dataintensive approach. Long time series are required because of considerable variability in the data and other methodological problems (Walters and Ludwig 1981; Myers et al. 1994). A widely used S-R based approach involves estimation of 'spawning biomass per recruit' (SPR) and its derivatives. A line of survivorship, the ratio of recruits/spawners, can be drawn on the S-R relationship. The slope of this line corresponds to a replacement level of fishing mortality $(1 / \mathrm{F})$. This approach has been used to select a survival ratio/ $\mathrm{F}$ value for use as a reference point $\left(F_{\text {low }}, F_{\text {med }}, F_{\text {high }}\right)$. It is recommended that a minimum of $30 \%$ of the maximum level of SPR is required to maintain replacement (Mace and Sissenwine 1993). The limit reference point most relevant to estimating extinction risk is $F_{\text {crash }}$ or $F_{\tau}$ which is the fishing mortality required to reduce a population to $1 / 1000$ of its original size (Mace and Sissenwine 1993; Mace 1994; Punt 2000). This BRP has been used as a metric 
of quasi-extinction in comparisons of the utility of decline criteria for threat listing (Punt 2000).

Demographic approaches can provide good metrics of vulnerability such as the potential jeopardy level $(F \varphi)$ or rebound potential using static lifehistory parameters. However, stage or age-based demographic parameters can be used in more detailed simulations or more detailed mechanistic exploration of extinction risk or to estimate the more complex population reference points typically used in fisheries management such as $F_{\text {crash }}$.

\section{Discussion}

We have outlined three broad approaches to measuring or inferring extinction risk depending on data availability: life histories and other rules of thumb, time series and demographic analyses. There are several issues worth highlighting and exploring further, including particularly the methodological assumptions and gaps.

\section{Assumptions}

Most of the methods outlined here make two important assumptions: (i) that populations exist in stable or equilibrium conditions with dynamics that can be described adequately by deterministic models, and (ii) that variance is intrinsic to the system rather than a result of sampling and parameter estimation.

There is increasing evidence that individuals, populations and communities exist in stochastic, changing environments with multiple alternative states or regimes (e.g. Scheffer et al. 2001; Benson and Trites 2002; Beaugrand et al. 2003). Climatic forcing results in shifting geographical distribution and carrying capacities of populations, and changing species dominance and ecosystem behaviour (e.g. Stenseth et al. 2002; Sharp 2003). Individuals may exhibit a high degree of phenotypic plasticity and species exhibit geographical variation in lifehistory traits, this variation should be considered when choosing model parameters (Roff 1992; Atkinson 1994; Hutchings 2002). When considering the deterministic methods for estimating population growth rate presented here, it should be borne in mind that stochastic estimates of population growth rates will always be lower than rates derived from deterministic methods (Hutchings 2001b, 2002). A large component of the observed variance may result from sampling error or biases resulting in uncertainty in parameter estimates. The estimation of $r$ from S-R time series requires many years of data, which may be scarce at low population levels leading to concern about the adequacy of the fitted model (Jennings 2001). While this may not present a problem for examining general life history relationships among species (e.g. Myers et al. 1999; Denney et al. 2002), the approaches may result in parameter estimates with a high degree of uncertainty on a stock-by-stock basis. Power to detect extinction depends strongly on sample variance. This issue, combined with uncertainty, needs far more attention (Dulvy et al. 2003). For example, the statistical power of a large-scale annual fish monitoring survey to detect decline and recovery in rare and depleted species was estimated for the English groundfish survey of the North Sea (ICES 2004a). The power to detect rapid decreases in abundance of rare and depleted species was poor on time scales $<10$ years. Even if populations recovered at the maximum potential rate of increase, 5-10 years of monitoring would be required to detect recovery (ICES 2004a).

\section{Methodological gaps}

Here we highlight four methodological areas which we believe require further consideration with respect to measuring extinction risk: geographical range size, ecological specificity, minimum viable population (MVP) size and comparability of threat criteria.

\section{Geographical range size}

There are three major routes to local, regional and global scale extinction in the sea: low productivity and/or high catchability, small geographical range size and high ecological specificity. The methods outlined here appear best suited to detecting declines or inferring extinctions associated with the first route. This is in contrast to the second and third routes, for which theory is less developed and there do not appear to be any practical methods of detecting such extinctions.

A key question is how small can the geographical range of a marine species be before there is a high risk of extinction? Many marine species exhibit an 'extent of occurrence' or 'area of occupancy' far in excess of the IUCN Red List thresholds. Extent of occurrence is the area within the shortest continuous imaginary boundary that can be drawn to encompass the taxon. Area of occupancy is the area 
actually occupied by a taxon within its extent of occurrence (Hilton-Taylor 2000). In order to qualify as threatened, the extent of occurrence must be $<20000 \mathrm{~km}^{2}$ and the area of occupancy must be $<2000 \mathrm{~km}^{2}$. Some small-bodied island endemic species have very small geographical ranges $\left(<100 \mathrm{~km}^{2}\right)$ and yet appear to persist (Robertson 2001). However, other coral reef fishes with small range sizes are threatened. Of 1677 coral reef fish species, 9.2\% had ranges (measured as extent of occurrence) $<50000 \mathrm{~km}^{2}$ and $24 \%$ had ranges $<80000 \mathrm{~km}^{2}$ (Hawkins et al. 2000). Approximately $55 \%$ of these restricted range coral reef fishes could also be classified as threatened under IUCN Red List criteria (Hawkins et al. 2000). This definition of restricted range $\left(80000 \mathrm{~km}^{2}\right)$ corresponds to an area of the size of the Australian Great Barrier Reef, but this would over-estimate the true extent of true habitat as it encompasses large stretches of deep water between the sparsely distributed reef atolls. Even this broader definition of a restricted range appears to have some utility in correctly identifying threatened species. Further work along these lines is needed to guide the selection of threat criteria based on geographical range size.

\section{Ecological specialization}

Habitat loss is a major cause of local, regional and global scale marine extinctions (Dulvy et al. 2003). The first documented global marine extinction of an invertebrate, the eelgrass limpet (Lottia alveus alveus, Lottidae) is attributed to the large scale loss of its habitat (Carlton et al. 1991). However, none of the methods outlined here could have predicted the disappearance of this habitat specialist. Habitat loss is the major cause of terrestrial extinctions (HiltonTaylor 2000). However, we have relatively little idea of the magnitude of habitat loss and the degree of habitat dependence of marine species (Stone 1995; Stone et al. 1996; Benaka 1999; Fagan et al. 2002).

The link between ecological specialization and extinction risk is poorly understood compared with body size and geographical range/endemism (McKinney 1997). It is relatively simple to conduct a posteriori analyses to identify traits such as diadromy, specialized habitats and specialized diets that are exhibited by species that face greater risk of extinction, particularly in freshwater fishes (McDowall 1992; Angermeier 1995; Parent and Schriml 1995). The only point we wish to make is that at present there is currently no validated $a$ priori framework for determining which traits are specializations and which are important for determining vulnerability to extinction (Futuyma and Moreno 1988). However there is at least one approach that may be worth of further examination. The niche-breadth hypothesis (Brown 1995) suggests that species narrowly adapted in one parameter (e.g. temperature tolerance) may also be narrowly adapted in other ecological parameters (e.g. diet) (Futuyma and Moreno 1988; Lawton et al. 1994; McKinney 1997). There is also evidence that niche narrowness is related to decreased local abundance and geographical range (Angermeier 1995). There is scope to search for such covarying patterns between putative specializations, niche breadth and extinction risk in marine fishes.

\section{Minimum viable population size}

The 'small population' paradigm is derived from a terrestrial perspective where a small population, possibly with a positive intrinsic rate of population increase, typically numbering less than 50-500 individuals, can decline as a result of environmental and demographic stochasticity or catastrophes (Caughley 1994; Simberloff 1998). To date few marine fishes have been considered using the 'small population' criteria of extinction risk assessment schemes, e.g. IUCN Red List. While there may be numerous individuals in a threatened population, the key question is what constitutes a 'small' or MVP for highly fecund marine fish. It may be fruitful to consider further the MVP size as there a number of arguments why marine broadcast spawners may require a higher MVP:

1 If the effective population size was less than the census population size. This may occur when there is a high variance in mating success because of assortative mating or high planktonic larval mortality. High larval mortality can mean that only a small minority of individuals achieve breeding success because such success relies on matching reproductive activity with oceanic conditions conducive to fertilization, larval survival and subsequent recruitment (Hedgecock 1994; Nielsen and Kenchington 2001; Hauser et al. 2002; Turner et al. 2002; Hutchings and Reynolds 2004).

2 If there is evidence for depensatory or Allee effects, where reduced reproductive output or increased predation mortality may result in declining population growth rate at small 
population sizes and a spiral towards extinction (Petersen and Levitan 2001; Dulvy et al. 2004; Gascoigne and Lipcius 2004).

3 If the population is one of a number of connected subpopulations. A higher threshold would be considered if there was evidence that the population receives a recruitment subsidy.

There are no data to indicate an appropriate extinction threshold for (2) and (3), but population genetic theory suggests the effective population size is at least 2-6 orders of magnitude less than the census population size (Hedgecock 1994; ICES $2004 \mathrm{c}$ ). Assuming the minimum viable population size is between 50 and 500 individuals, the equivalent MVPs for highly fecund species could be 50 000-500 000. It is difficult to evaluate this 'back of the envelope' calculation and the only evidence we have to support this is the observation that the last known census population size of the Icelandic spring spawning herring was 700000 in 1972. The current population size and the fate of this stock is unknown (Jakobsson et al. 1969; Jakobsson 1980; Beverton 1992). There is clearly scope for exploring the minimum viable population size of species with potentially small effective population sizes, such as broadcast spawning fishes and invertebrates.

\section{Comparability of threat criteria}

Possibly the most pressing issues for fisheries scientists to consider is (1) whether simple threat criteria, such as decline thresholds accurately reflect true risk of extinction in marine fishes, and (2) how threat criteria compare to standard fisheries reference points (Smith et al. 1993; Matsuda et al. 1997; Butterworth 2000; FAO 2000; Powles et al. 2000; Punt 2000; Sadovy 2001; Reynolds et al. 2002).

As there are few documented recent global extinctions of marine fishes, the direct measurement of extinction risk is not possible and we are left with proxy methods for inferring or estimating risk. Therefore, estimating the 'true' risk of extinction can only be addressed using statistical or simulation models of population dynamics. The modelling approach is limited by a poor understanding of population dynamics at small population sizes, in particular the likelihood of depensatory or Allee effects occurring. Modelling approaches can therefore only estimate quasiextinction or the probability of crossing an arbitrary threshold, e.g. $5 \%$ of virgin population size (Pope et al. 2000), or the level of fishing mortality that causes the population to decline to $1 / 1000$ th of the virgin population size, $F_{\text {crash }}$ (Punt 2000). An alternative approach would be to use individual or behaviour-based population viability models. However, these models have high data requirements that put their use beyond the scope of most marine organisms (e.g. Sutherland and Gill 2001; Stephens et al. 2002). At present, population simulation appears to be the most promising approach for comparing extinction risk criteria within the constraints of defining extinction or providing a defensible level of quasi-extinction.

Two studies have compared extinction risk metrics using simulation approaches. The southern bluefin tuna was listed as 'critically endangered' under IUCN Red List criteria based on population decline of $80 \%$ within three generations (Matsuda et al. 1998). Three methods suggested it was unlikely that the southern bluefin tuna would become quasi-extinct within the next three or five generations (Matsuda et al. 1997) and it was concluded that the decline threshold of $80 \%$ may be too conservative for species with large population sizes (Matsuda et al. 1998). Age-structured population projections of six Australian fishes were used to compare IUCN Red List decline criteria and fisheries reference points (Punt 2000). There was a substantial probability $(9-40 \%)$ of incorrectly classifying species that were exploited sustainably as threatened (Punt 2000). Threat listings were correctly assigned to species being exploited to extinction in $80-100 \%$ of cases.

There is a need to balance rational exploitation and appropriate conservation over a wide range of exploited species and this might be achieved by comparing extinction risk metrics or threat indicators with 'real world' metrics using the hits, misses and false alarms framework derived from signal detection theory (ICES 2003a; Rice 2003; ICES 2004b). A good indicator or criterion will only provide hits and minimize the rate of misses and false alarms. There are two types of hit: a true positive and a true negative resulting in $2 \times 2$ table of outcomes (Table 3). In this context a true positive would be where the species is listed under the selection criterion and is genuinely at risk of extinction, and a true negative is where a species did not meet the criterion and was also safe (Table 3). A false alarm is where a species meets the criterion yet is not at risk of extinction, and a miss is where a species does not meet the criterion yet is in danger. Both the above studies indicate that the IUCN Red List decline 
Table 3 Hits, misses and false alarms framework for assessing the performance of extinction risk criteria against a 'real world' metric.

The 'real world' metric can represent the political, social and economic desires of society. In the case of exploited species, the 'real world' metric may be a measure of sustainable or unsustainable exploitation derived from fisheries reference points. There are two possible responses of extinction criteria: at risk of extinction and not at risk of extinction.

criteria have a high hit rate but may be prone to false alarms. But the truth is that we just do not know yet. There is considerable scope to extend the Punt (2000) and Matsuda et al. (1998) approaches within the hits, misses and false alarms framework to determine decline thresholds which optimize the balance between rational exploitation and appropriate conservation over a wider range of exploited species.

\section{Conclusion}

Much of this review has focussed on deterministic methods for assessing extinction risk. These require minimal data but assume equilibrium conditions. Use of simple methods is not meant to imply that the level of scientific rigour required in the often resource-limited and pragmatic realm of conservation biology should be reduced. Instead we advocate a two-tiered approach. First, simple methods can be used for rapid assessments of large numbers of populations and species to identify those that are potentially vulnerable. Then these species can be subjected to more detailed and rigorous population analyses. Assessments of extinction risk of marine fishes cut across many disciplines, including population biology, ecology and behaviour. We need continued effort to develop and refine both short cuts and detailed methods for making accurate assessments.

\section{Acknowledgements}

The authors thank DEFRA (MFD 0729) and NERC (NER/A/S/2001/01075) for funding this research and we thank D. Herdson and P. Cox (National Marine Aquarium, Plymouth, UK) for providing data and A. Bräutigam, T. J. Donaldson, J.A. Hutchings and S. A. Fowler for valuable discussion.

\section{References}

Aldebert, Y. (1997) Demersal resources of the Gulf of Lions (NW Mediterranean). Impact of exploitation on fish diversity. Vie et Millieu 47, 275-284.

Allsop, D.J. and West, S.A. (2003) Changing sex at the same relative body size. Nature 425, 783-784.

Angermeier, P.L. (1995) Ecological attributes of extinction-prone species: loss of freshwater fishes of Virginia. Conservation Biology 9, 143-158.

Anonymous (2000) Status Review of Smalltooth Sawfish (Pristis pectinata). National Marine Fisheries Service, Office of Protected Resources, Silver Springs, MD, $71 \mathrm{pp}$.

Atkinson, D. (1994) Temperature and organism size - a biological law for ectotherms. Advances in Ecological Research 25, 158.

Au, D.W. and Smith, S.E. (1997) A demographic method with population density compensation for estimating productivity and yield per recruit of the leopard shark (Triakis semifasciata). Canadian Journal of Fisheries and Aquatic Sciences 54, 415-420.

Baum, J.K., Myers, R.A., Kehler, D.G., Worm, B., Harley, S.J. and Doherty, P.A. (2003) Collapse and conservation of shark populations in the northwest Atlantic. Science 299, 389-392.

Beaugrand, G., Brander, K.M., Lindley, J.A., Souissi, S. and Reid, P.C. (2003) Plankton effect on cod recruitment in the North Sea. Nature 426, 661-664.

Bellwood, D.R., Hoey, A.S. and Choat, J.H. (2003) Limited functional redundancy in high diversity systems: resilience and ecosystem function on coral reefs. Ecology Letters 6, 281-285.

Benaka, L.R. (1999) Fish habitat: essential fish habitat and rehabilitation. American Fisheries Society Symposium, Bethesda, Maryland.

Benson, A.J. and Trites, A.W. (2002) Ecological effects of regime shifts in the Bering Sea and eastern North Pacific Ocean. Fish and Fisheries 3, 95-113.

Benton, T.G. and Grant, A. (1999) Elasticity analysis as an important tool in evolutionary and population ecology. Trends in Ecology and Evolution 14, 467-471. 
Beverton, R.J.H. (1963) Maturation, growth and mortality of Clupeid and Engraulid stocks in relation to fishing. Rapports et Procés-Verbaux des Réunions, Conseil International pour l'Exploration de la Mer 154, 44-67.

Beverton, R.J.H. (1990) Small pelagic fish and the threat of fishing: are they endangered? Journal of Fish Biology 37, 5-16.

Beverton, R.J.H. (1992) Patterns of reproductive strategy parameters in some marine teleost fishes. Journal of Fish Biology 41, 137-160.

Beverton, R.J.H. and Holt, S.J. (1957) On the dynamics of exploited fish populations. Chapman \& Hall, London.

Brander, K. (1981) Disappearance of common skate Raia batis from Irish Sea. Nature 290, 48-49.

Brown, J.H. (1995) Macroecology. University of Chicago Press, London.

Burgman, M.A., Grimson, R.C. and Ferson, S. (1995) Inferring threat from scientific collections. Conservation Biology 9, 923-928.

Butterworth, D.S. (2000) Possible interpretation problems for the current CITES listing criteria in the context of marine fish species under commercial harvest. Population Ecology 42, 29-35.

Caddy, J.F. and Mahon, R. (1995) Reference points for fisheries management. FAO Fisheries Technical Paper, Rome, No. 347, 83 pp.

Carlton, J.T., Vermeij, G.J., Lindberg, D.R., Carlton, D.A. and Dudley, E.C. (1991) The 1st historical extinction of a marine invertebrate in a basin - the demise of the eelgrass limpet Lottia alveus. Biological Bulletin 180, 7280.

Carlton, J.T., Geller, J.B., Reaka-Kudla, M.L. and Norse, E.A. (1999) Historical extinctions in the sea. Annual Review of Ecology and Systematics 30, 525-538.

Casey, J. and Myers, R.A. (1998) Near extinction of a large, widely distributed fish. Science 281, 690-692.

Caswell, H. (1989) Matrix Population Models. Sinauer, Sunderland, MA.

Caughley, G. (1994) Directions in conservation biology. Journal of Animal Ecology 63, 215-244.

Charnov, E.L. (1993) Life History Invariants. Oxford University Press, Oxford.

Clark, W.G. and Hare, S.R. (2002) Effects of climate and stock size on recruitment and growth of Pacific halibut. North American Journal of Fisheries Management 22, 852862.

Cook, R.M. (1998) A sustainability criterion for the exploitation of North Sea cod. International Council for the Exploration of the Seas, Journal of Marine Science $\mathbf{5 5}$, 1061-1070.

Cortés, E. (2000) Life history patterns and correlations in sharks. Reviews in Fisheries Science 8, 299-344.

Cortés, E. (2002) Incorporating uncertainty into demographic modelling: application to shark populations and their conservation. Conservation Biology 18, 10481062 .
Crouse, D.T., Crowder, L.B. and Caswell, H. (1993) A stage-based population model for loggerhead sea turtles and implications for conservation. Ecology 68, 14121423.

Denney, N.H., Jennings, S. and Reynolds, J.D. (2002) Life history correlates of maximum population growth rates in marine fishes. Proceedings of the Royal Society of London, B 269, 2229-2237.

Dennis, B., Munholland, P.L. and Scott, J.M. (1991) Estimation of growth and extinction parameters for endangered species. Ecological Monographs 61, 115143.

Dulvy, N.K. and Reynolds, J.D. (2002) Predicting extinction vulnerability in skates. Conservation Biology 16, $440-450$.

Dulvy, N.K., Metcalfe, J.D., Glanville, J., Pawson, M.G. and Reynolds, J.D. (2000) Fishery stability, local extinctions and shifts in community structure in skates. Conservation Biology 14, 283-293.

Dulvy, N.K., Sadovy, Y. and Reynolds, J.D. (2003) Extinction vulnerability in marine populations. Fish and Fisheries 4, 25-64.

Dulvy, N.K., Freckleton, R.P. and Polunin, N.V.C. (2004) Coral reef cascades and the indirect effects of predator removal by exploitation. Ecology Letters 7, 410-416.

Fagan, W.F., Meir, E., Prendergast, J., Folarin, A. and Karieva, P. (2001) Characterizing population variability for 758 species. Ecology Letters 4, 132-138.

Fagan, W.F., Unmack, P.J., Burgess, C. and Minckley, W.L. (2002) Rarity, fragmentation, and extinction risk in desert fishes. Ecology 83, 3250-3256.

FAO (2000) An appraisal of the suitability of the CITES criteria for listing commercially exploited aquatic species. Food and Agriculture Organisation, Rome, Fisheries Circular, No. 954, 66 pp.

Francis, M.P., Ó Maolagáin, C. and Stevens, D. (2001) Age, growth, and sexual maturity of two New Zealand endemic skates, Dipturus nasutus and D. innominatus. New Zealand Journal of Marine and Freshwater Research 35, 831-842.

Freckleton, R.P. (2002) Phylogenetic analysis and comparative data: a test and review of evidence. American Naturalist 160, 712-726.

Frisk, M.G., Miller, T.J. and Fogarty, M.J. (2001) Estimation of biological parameters in elasmobranch fishes: a comparative life history study. Canadian Journal of Fisheries and Aquatic Sciences 58, 969-981.

Froese, R. and Binohlan, C. (2000) Empirical relationships to estimate asymptotic length, length at first maturity and length at maximum yield per recruit in fishes, with a simple method to evaluate length frequency data. Journal of Fish Biology 56, 758-773.

Froese, R. and Palomares, M.L.D. (2000) Growth, natural mortality, length-weight relationship, maximum length and length-at-first-maturity of the coela- 
canth Latimeria chalumnae. Environmental Biology of Fishes 58, 45-52.

Futuyma, D.J. and Moreno, G. (1988) The evolution of ecological specialization. Annual Review of Ecology and Systematics 19, 207-233.

Gabriel, W.L., Sissenwine, M.P. and Overholtz, W.J. (1989) Analysis of spawning stock biomass per recruit: an example for Georges Bank haddock. North American Journal of Fisheries Management 9, 383-391.

Garcia, S.M. (1996) The precautionary approach to fisheries and its implications for fisheries research, technology, and management: an updated review. FAO Fisheries Technical Paper, Rome, No. 350/2, 75 pp.

Gascoigne, J. and Lipcius, R.N. (2004) Allee effects in marine systems. Marine Ecology Progress Series 269, 4959.

Grogan, C.S. and Boreman, J. (1998) Estimating the probability that historical populations of fish species are extirpated. North American Journal of Fisheries Management 18, 522-529.

Groombridge, B. and Jenkins, M.D. (2000) Global Biodiversity: Earth's Living Resources in the 21st Century. World Conservation Monitoring Centre, World Conservation Press, Cambridge.

Hauser, L., Adcock, G.J., Smith, P.J., Ramirez, J.H.B. and Carvalho, G.R. (2002) Loss of microsatellite diversity and low effective population size in an overexploited population of New Zealand snapper (Pagrus auratus). Proceedings of the National Academy of Sciences 99 , 11742-11747.

Hawkins, J.P., Roberts, C.M. and Clark, V. (2000) The threatened status of restricted-range coral reef fish species. Animal Conservation 3, 81-88.

Hedgecock, D. (1994) Does variance in reproductive success limit effective population sizes of marine organisms? In: Genetics and Evolution of Aquatic Organisms (ed. A.R. Beaumont). Chapman \& Hall, London, pp. 122-134.

Hendrick, P.W., Lacy, R.C., Allendorf, F.W. and Soule, M.E. (1996) Directions in conservation biology: comments on Caughley. Conservation Biology 10, 1312-1320.

Heppell, S.S., Crowder, L.B. and Menzel, T.R. (1999) Life table analysis of long-lived marine species with implications for conservation and management. In: Life in the Slow Lane: Ecology and Conservation of Long-lived Marine Animals (ed. J.A. Musick). American Fisheries Society, Bethesda, Maryland, pp. 137-147.

Heppell, S.S., Crouse, D.T. and Crowder, L.B. (2000) Using matrix models to focus research and management efforts in conservation. In: Quantitative Methods for Conservation Biology (eds S. Ferson and M.A. Burgman). Springer, New York, pp. 148-168.

Hilton-Taylor, C. (2000) IUCN Red List of Threatened Species. International Union for the Conservation of Nature, Gland, Switzerland, 61 pp.
Hoenig, J.M. (1983) Empirical use of longevity data to estimate mortality rates. Fisheries Bulletin 81, 898-903.

Holmes, E.E. (2001) Estimating risks in declining populations with poor data. Proceedings of the National Academy of Sciences of the United States of America 98, 50725077.

Hudson, E. and Mace, G. (1996) Marine Fish and the IUCN Red List of Threatened Fish Species. Zoological Society of London, London.

Hutchings, J.A. (2000) Collapse and recovery of marine fishes. Nature 406, 882-885.

Hutchings, J.A. (2001a) Conservation biology of marine fishes: perceptions and caveats regarding assignment of extinction risk. Canadian Journal of Fisheries and Aquatic Sciences 58, 108-121.

Hutchings, J.A. (2001b) Influence of growth and survival costs of reproduction on Atlantic cod, Gadus morhua, population growth rate. Canadian Journal of Fisheries and Aquatic Science 56, 1612-1623.

Hutchings, J.A. (2001c) Influence of population decline, fishing, and spawner variability on the recovery of marine fishes. Journal of Fish Biology 59A, 306-322.

Hutchings, J.A. (2002) Life histories. In: Handbook of Fish and Fisheries (eds P.J.B. Hart and J.D. Reynolds). Blackwell Science, Oxford, pp. 149-174.

Hutchings, J.A. and Reynolds, J.D. (2004) Marine fish population collapses: consequences for recovery and extinction risk. BioScience 54, 297-309.

ICES (2003a) Report of the ICES Working Group of Ecosystem Effects of Fishing Activities 2003. International Council for the Exploration of the Seas, Copenhagen, No. ICES CM 2003/ACE:05, 199 pp.

ICES (2003b) Report of the ICES Working Group of Fish Ecology 2003. International Council for the Exploration of the Seas, Copenhagen, No. ICES CM 2003/G:04, 110 pp.

ICES (2004a) Report of the ICES Working Group of Ecosystem Effects of Fishing Activities 2004. International Council for the Exploration of the Seas, Copenhagen (in press).

ICES (2004b) Report of the ICES Working Group of Fish Ecology 2004. International Council for the Exploration of the Seas, Copenhagen, No. ICES CM 2004/G:09, 246 pp.

ICES (2004c) Report of the Working Group on the Application of Genetics in Fisheries and Mariculture. ICES, Copenhagen, ICES CM, No. 2004/F:04, 44 pp.

IUCN (1996) 1996 IUCN Red List of Threatened Animals. IUCN, Gland, Switzerland.

IUCN (2001) IUCN Red List Categories and Criteria: version 3.1. IUCN Species Survival Commission, Gland Switzerland and Cambridge, UK, 30 pp.

Jakobsson, J. (1980) Exploitation of the Icelandic spring and summer-spawning herring in relation to fisheries management. Rapports et Procès-Verbaux des Réunions du 
Conseil International pour l'Exploration de la Mer 177, 2342.

Jakobsson, J., Vilhjálmsson, H. and Schopka, S.A. (1969) On the biology of the Icelandic herring stocks. Rit Fiskideildar 4, 1-16.

Jennings, S. (2001) Patterns and prediction of population recovery in marine reserves. Reviews in Fish Biology and Fisheries 10, 209-231.

Jennings, S. and Beverton, R.J.H. (1991) Intraspecific variation in the life history tactics of Atlantic herring (Clupea harengus L.) stocks. International Council for Exploration of the Seas, Journal of Marine Science $\mathbf{4 8}$, $117-125$.

Jennings, S. and Kaiser, M.J. (1998) The effects of fishing on marine ecosystems. Advances in Marine Biology 34, 201-352.

Jennings, S., Reynolds, J.D. and Mills, S.C. (1998) Life history correlates of responses to fisheries exploitation. Proceedings of the Royal Society of London, B 265, 333339.

Jennings, S., Reynolds, J.D. and Polunin, N.V.C. (1999) Predicting the vulnerability of tropical reef fishes to exploitation using phylogenies and life histories. Conservation Biology 13, 1466-1475.

Jensen, A.L. (1997) Origin of the relation between $K$ and $L_{\text {inf }}$ and synthesis of relations among life history parameters. Canadian Journal of Fisheries and Aquatic Sciences 54, 987-989.

Jones, R. (1981) The use of length composition data in fish stock assessments (with notes on VPA and cohort analysis). FAO, Rome, Fisheries Circular, No. 734, 60 pp. Jukic-Peladic, S., Vrgoc, N., Krstulovic-Sifner, S., Piccinetti, C., Piccinetti-Manfrin, G., Marano, G. and Ungaro, N. (2001) Long-term changes in demersal resources of the Adriatic Sea: comparison between trawl surveys carried out in 1948 and 1998. Fisheries Research 53, 95-104.

Lawton, J.H., Nee, S., Letcher, A.J. and Harvey, P.H. (1994) Animal distributions: patterns and processes. In: Large Scale Ecology and Conservation Biology (eds P.J. Edwards, R.M. May and N.R. Webb). Blackwell Scientific Publishers, London, pp. 41-58.

MacDonald, D.S., Pope, J.G., Daan, N. and Reynolds, J.D. (1994) Impact of Fishing on Non-target Species: Final Report to the Commission of the European Communities from MAFF Directorate of Fisheries Research, RIVO and the University of East Anglia. Ministry of Agriculture, Fisheries and Food, Directorate of Fisheries Research, Lowestoft, 84 pp.

Mace, P.M. (1994) Relationships between common biological reference points used as thresholds and targets of fisheries management strategies. Canadian Journal of Fisheries and Aquatic Sciences 51, 110-122.

Mace, G.M. (1995) Classification of threatened species and its role in conservation planning. In: Extinction Rates (eds J.H. Lawton and R.M. May). Oxford University Press, Oxford, UK, pp. 197-213.

Mace, G.M. and Hudson, E.J. (1999) Attitudes towards sustainability and extinction. Conservation Biology 13 , 242-246.

Mace, G.M. and Lande, R. (1991) Assessing extinction threats: toward a reevaluation of IUCN threatened species categories. Conservation Biology 5, 148-157.

Mace, P.M. and Sissenwine, M.P. (1993) How much spawning per recruit is enough? Canadian Special Publication Fisheries and Aquatic Sciences 120, 101-118.

Magurran, A.E. and Henderson, P.A. (2003) Explaining the excess of rare species in natural species abundance distributions. Nature 422, 714-716.

Matsuda, H., Yahara, T. and Uozumi, Y. (1997) Is tuna critically endangered? Extinction risk of a large and overexploited population. Ecological Research 12, 345-356.

Matsuda, H., Takenaka, Y., Yahara, T. and Uozumi, Y. (1998) Extinction risk assessment of declining wild populations: the case of the southern bluefin tuna. Researches on Population Ecology 40, 271-278.

Matsuda, H., Yahara, T. and Kaneko, Y. (2000) Extinction risk assessment of threatened species. Population Ecology 42, 3-4.

McDowall, R.M. (1992) Particular problems for the conservation of diadromous fishes. Aquatic Conservation Marine and Freshwater Ecosystems 2, 351-355.

McKinney, M.L. (1997) Extinction vulnerability and selectivity: combining ecological and paleontological views. Annual Review of Ecology and Systematics 28, 495-516.

Musick, J.A. (1998) Endangered marine fishes: criteria and identification of North American stocks at risk. Fisheries 2, 28-30.

Musick, J.A. (1999) Criteria to define extinction risk in marine fishes. Fisheries 24, 6-14.

Musick, J.A., Harbin, M.M., Berkeley, S.A. et al. (2000) Marine, estuarine, and diadromous fish stocks at risk of extinction in North America (exclusive of Pacific salmonids). Fisheries 25, 6-30.

Myers, R.A. (2001) Stock and recruitment: generalizations about maximum reproductive rate, density dependence, and variability using meta-analytic approaches. International Council for Exploration of the Seas, Journal of Marine Science 58, 937-951.

Myers, R.A., Rosenberg, A.A., Mace, P.M., Barrowman, N. and Restrepo, V.R. (1994) In search of thresholds for recruitment overfishing. International Council for Exploration of the Seas, Journal of Marine Science 51, 191-205.

Myers, R.A., Mertz, G. and Fowlow, P.S. (1997) Maximum population growth rates and recovery times for Atlantic cod, Gadus morhua. Fishery Bulletin 95, 762-772.

Myers, R.A., Brown, K.G. and Barrowman, N.J. (1999) The maximum reproductive rate of fish at low population 
sizes. Canadian Journal of Fisheries and Aquatic Sciences 56, 2404-2419.

Nielsen, E.E. and Kenchington, E. (2001) A new approach to prioritizing marine fish and shellfish populations for conservation. Fish and Fisheries 2, 328-343.

O'Brien, C.M., Fox, C.J., Planque, B. and Casey, J. (2000) Climate variability and North Sea cod. Nature 404, 142.

Olsen, E.M., Heino, M., Lilly, G.R., Morgan, M.J., Brattey, J., Ernande, B. and Dieckamm, J. (2004) Maturation trends indicative of rapid evolution preceded the collapse of northern cod. Nature 428, 932-935.

Parent, S. and Schriml, L.M. (1995) A model for the determination of fish species at risk based upon lifehistory traits and ecological data. Canadian Journal of Fisheries and Aquatic Science 52, 1768-1781.

Pauly, D. (1980) On the interrelationships between natural mortality, growth parameters, and mean environmental temperature in 175 fish stocks. Journal du Conseil International pour l' Exploration de la Mer 39, 175-192.

Pauly, D. (1998) Tropical fishes: patterns and propensities. Journal of Fish Biology 53, 1-17.

Petersen, C.W. and Levitan, D.R. (2001) The Allee effect: a barrier to recovery by exploited species. In: Conservation of Exploited Species (eds J.D. Reynolds, G.M. Mace, K.H. Redford and J.G. Robinson). Cambridge University Press, Cambridge, pp. 281-300.

Pitcher, T.J. (2001) Fisheries managed to rebuild ecosystems? Reconstructing the past to salvage the future. Ecological Applications 11, 601-617.

Pope, J.G., MacDonald, D.S., Daan, N., Reynolds, J.D. and Jennings, S. (2000) Gauging the vulnerability of nontarget species to fishing. International Council for Exploration of the Seas, Journal of Marine Science 57, 689-696.

Powles, H., Bradford, M.J., Bradford, R.G., Doubleday, W.G., Innes, S. and Levings, C.D. (2000) Assessing and protecting endangered marine species. International Council for Exploration of the Seas, Journal of Marine Science 57, 669-676.

Punt, A.E. (2000) Extinction of marine renewable resources: a demographic analysis. Population Ecology 42, 19.

Purvis, A., Gittleman, J.L., Cowlishaw, G. and Mace, G.M. (2000a) Predicting extinction risk in declining species. Proceedings of the Royal Society of London, Series B 267, 1947-1952.

Purvis, A., Jones, K.E. and Mace, G.M. (2000b) Extinction. Bioessays 22, 1123-1133.

Reed, J.M. (1996) Using statistical probability to increase confidence of inferring species extinction. Conservation Biology 10, 1283-1285.

Reynolds, J.D. (2003) Life histories and extinction risk. In: Macroecology (ed. T.J. Blackburn). Blackwell Publishing, Oxford, pp. 195-217.

Reynolds, J.D., Jennings, S. and Dulvy, N.K. (2001) Life histories of fishes and population responses to exploita- tion. In: Conservation of Exploited Species (eds J.D. Reynolds, G.M. Mace, K.H. Redford and J.G. Robinson). Cambridge University Press, Cambridge, pp. 147-168.

Reynolds, J.D., Dulvy, N.K. and Roberts, C.M. (2002) Exploitation and other threats to fish conservation. In: Fish and Fisheries Handbook (eds P.J.B. Hart and J.D. Reynolds). Blackwell Science, Oxford, pp. 319-341.

Rice, J. (2003) Environmental health indicators. Ocean and Coastal Management 46, 235-259.

Rickman, S.J., Dulvy, N.K., Jennings, S. and Reynolds, J.D. (2000) Recruitment variation associated with fecundity in marine fishes. Canadian Journal of Fisheries and Aquatic Sciences 57, 116-124.

Roberts, C.M. (2003) Our shifting perspectives on the oceans. Oryx 37, 166-177.

Roberts, C.M. and Hawkins, J.P. (1999) Extinction risk in the sea. Trends in Ecology and Evolution 14, 241-246.

Roberts, D.L. and Solow, A.R. (2003) When did the dodo become extinct? Nature 426, 245.

Robertson, D.R. (2001) Population maintenance among tropical reef fishes: inferences from small-island endemics. Proceedings of the National Academy of Sciences $\mathbf{9 8}$, 5667-5670.

Rochet, M.-J. (2000) A comparative approach to life history strategies and tactics among four orders of teleost fish. International Council for the Exploration of the Seas, Journal of Marine Science 57, 228-239.

Rochet, M.-J. and Trenkel, V. (2003) Which community indicators can measure the impact of fishing? A review and proposals. Canadian Journal of Fisheries and Aquatic Sciences 60, 86-99.

Roff, D.A. (1992) The Evolution of Life Histories. Chapman and Hall, New York.

Rogers, S.I. and Ellis, J.R. (2000) Changes in the demersal fish assemblages of British coastal waters during the 20th century. International Council for Exploration of the Seas, Journal of Marine Science 57, $866-881$.

Sæther, B.-E. and Engen, S. (2003) Routes to extinction. In: Macroecology (eds K.J. Gaston and T.J. Blackburn). Blackwell Publishing, Oxford, pp. 218-236.

Sadovy, Y. (2001) The threat of fishing to highly fecund fishes. Journal of Fish Biology 59A, 90-108.

Sadovy, Y. and Cheung, W.L. (2003) Near extinction of a highly fecund fish: the one that nearly got away. Fish and Fisheries 4, 86-99.

Scheffer, M., Carpenter, S., Foley, J.A., Folke, C. and Walker, B. (2001) Catastrophic shifts in ecosystems. Nature 413, 591-596.

Sharp, G.D. (2003) Future Climate Changes and Regional Fisheries: A Collaborative Analysis. Food and Agriculture Organisation, Rome, Fisheries Technical Paper, No. 452, 75 pp.

Simberloff, D.S. (1998) Small and declining populations. In: Conservation Science and Action (ed. W.J. Sutherland). Blackwell Science, Oxford, pp. 116-134. 
Smith, S.J., Hunt, J.J. and Rivard, D. (1993) Risk evaluation and biological reference points for fisheries management. Canadian Special Publication of Fisheries and Aquatic Sciences 120, 1-422.

Smith, S.E., Au, D.W. and Show, C. (1999) Intrinsic rebound potentials of 26 species of Pacific sharks. Marine and Freshwater Research 49, 663-678.

Smith-Vaniz, W.F., Colette, B.B. and Luckhurst, B.E. (1999) Fishes of Bermuda, Special Publication No. 4. American Society of Ichthyology and Herptology, Allen Press, Lawrence, KS.

Solow, A.R. (1993a) Inferring extinction from sighting data. Ecology 74, 962-964.

Solow, A.R. (1993b) Inferring extinction in a declining population. Journal of Mathematical Biology 32, 79-82.

Stenseth, N.C., Mysterud, A., Ottersen, G., Hurrell, J.W., Chan, K.-S. and Lima, M. (2002) Ecological effects of climate fluctuations. Science 297, 1292-1296.

Stephens, P.A., Frey-Roos, F., Arnold, W. and Sutherland, W.J. (2002) Sustainable exploitation of social species: a test and comparison of models. Journal of Applied Ecology 39, 629-642.

Stevens, J.D., Bonfil, R., Dulvy, N.K. and Walker, P. (2000) The effects of fishing on sharks, rays and chimaeras (chondrichthyans), and the implications for marine ecosystems. International Council for Exploration of the Seas, Journal of Marine Science 57, 476-494.

Stobutzki, I., Miller, M. and Brewer, D. (2001) Sustainability of fishery bycatch: a process for assessing highly diverse and numerous bycatch. Environmental Conservation 28, 167-181.
Stone, L. (1995) Biodiversity and habitat destruction: a comparative study of model forest and coral reef ecosystems. Proceedings of the Royal Society of London, B 261, 381-388.

Stone, L., Eilam, E., Abelson, A. and Ilan, M. (1996) Modelling coral reef biodiversity and habitat destruction. Marine Ecology Progress Series 134, 299-302.

Sutherland, W.J. and Gill, J.A. (2001) The role of behaviour in studying sustainable exploitation. In: Conservation of Exploited Species (eds J.D. Reynolds, G.M. Mace, K.H. Redford and J.G. Robinson). Cambridge University Press, Cambridge, pp. 259-280.

Tegner, M.J., Basch, L.V. and Dayton, P.K. (1996) Near extinction of an exploited marine invertebrate. Trends in Ecology and Evolution 11, 278-280.

Turner, T.F., Wares, J.P. and Gold, J.R. (2002) Genetic effective size is three orders of magnitude smaller than adult census size in an abundant, estuarine-dependent marine fish (Sciaenops ocellatus). Genetics 162, 13291339.

Walters, C.J. and Ludwig, D. (1981) Effects of measurement errors on the assessment of stock-recruitment relationships. Canadian Journal of Fisheries and Aquatic Sciences 38, 704-710.

Wolff, W. (2000) Causes of extirpations in the Wadden Sea, an estuarine area in the Netherlands. Conservation Biology 14, 876-885.

WSSD (2002) Plan of Implementation of the World Summit on Sustainable Development. UN Department of Economic and Social Affairs, Division of Sustainable Development, New York. 